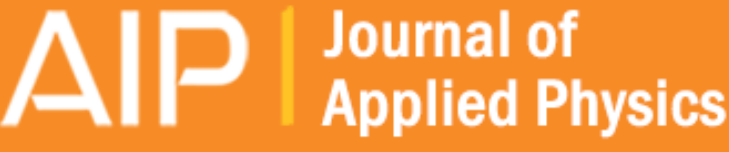

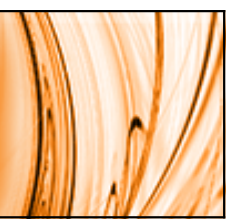

\section{Distinguishing triplet energy transfer and trap-assisted recombination in multi-color organic light-emitting diode with an ultrathin phosphorescent emissive layer}

Qin Xue, Guohua Xie, Shouyin Liu, Ping Chen, Yi Zhao, and Shiyong Liu

Citation: Journal of Applied Physics 115, 114504 (2014); doi: 10.1063/1.4869056

View online: http://dx.doi.org/10.1063/1.4869056

View Table of Contents: http://scitation.aip.org/content/aip/journal/jap/115/11?ver=pdfcov

Published by the AIP Publishing

\section{Articles you may be interested in}

Enhanced efficiency and reduced roll-off in nondoped phosphorescent organic light-emitting devices with triplet multiple quantum well structures

Appl. Phys. Lett. 97, 083304 (2010); 10.1063/1.3483131

Delayed electroluminescence in small-molecule-based organic light-emitting diodes: Evidence for triplet-triplet annihilation and recombination-center-mediated light-generation mechanism

J. Appl. Phys. 98, 013510 (2005); 10.1063/1.1937472

Delayed recombination of detrapped space-charge carriers in poly[2-methoxy-5-( 2 -ethyl-hexyloxy)-1,4phenylene vinylene]-based light-emitting diode

J. Appl. Phys. 97, 114505 (2005); 10.1063/1.1914949

White organic light-emitting diode comprising of blue fluorescence and red phosphorescence

Appl. Phys. Lett. 86, 113507 (2005); 10.1063/1.1879108

Confinement of triplet energy on phosphorescent molecules for highly-efficient organic blue-light-emitting devices Appl. Phys. Lett. 83, 569 (2003); 10.1063/1.1594834

\section{A|P| $\begin{aligned} & \text { Journal of } \\ & \text { Applied Physics }\end{aligned}$}

Journal of Applied Physics is pleased to announce André Anders as its new Editor-in-Chief 


\title{
Distinguishing triplet energy transfer and trap-assisted recombination in multi-color organic light-emitting diode with an ultrathin phosphorescent emissive layer
}

\author{
Qin Xue, ${ }^{1, a), b)}$ Guohua Xie, ${ }^{2, a)}$ Shouyin Liu, ${ }^{1}$ Ping Chen, ${ }^{2}$ Yi Zhao, ${ }^{2}$ and Shiyong Liu ${ }^{2}$ \\ ${ }^{1}$ Department of Physical Science and Technology, Central China Normal University, Wuhan 430079, \\ People's Republic of China \\ ${ }^{2}$ State Key Laboratory on Integrated Optoelectronics, College of Electronic Science and Engineering, \\ Jilin University, Changchun 130012, People's Republic of China
}

(Received 8 December 2013; accepted 7 March 2014; published online 19 March 2014)

\begin{abstract}
An ultrathin layer of deep-red phosphorescent emitter tris(1-phenylisoquinoline) iridium (III) (Ir(piq) 3 ) is inserted within different positions of the electron blocking layer fac-tris (1-phenylpyrazolato$N, C^{2^{\prime}}$ )-iridium(III) $\left(\mathrm{Ir}(\mathrm{ppz})_{3}\right)$ to distinguish the contribution of the emission from the triplet exciton energy transfer/diffusion from the adjacent blue phosphorescent emitter and the trap-assisted recombination from the narrow band-gap emitter itself. The charge trapping effect of the narrow band-gap deep-red emitter which forms a quantum-well-like structure also plays a role in shaping the electroluminescent characteristics of multi-color organic light-emitting diodes. By accurately controlling the position of the ultrathin sensing layer, it is considerably easy to balance the white emission which is quite challenging for full-color devices with multiple emission zones. There is nearly no energy transfer detectable if $7 \mathrm{~nm}$ thick $\operatorname{Ir}(\mathrm{ppz})_{3}$ is inserted between the blue phosphorescent emitter and the ultrathin red emitter. (C) 2014 AIP Publishing LLC. [http://dx.doi.org/10.1063/1.4869056]
\end{abstract}

\section{INTRODUCTION}

Organic light-emitting diodes (OLEDs) are a promising technology for flat panel display. In particular, white OLEDs (WOLEDs) are of foremost interest for full-color display and solid-state lighting sources. ${ }^{1-6}$ Charge carriers distribution in the emissive zone has great influence on the color stability and radiative recombination rate of WOLEDs with multiple emitter dopants or multiple emissive layers. ${ }^{7-9}$ Triplet exciton management has been known as one of the key factors affecting the efficiencies of phosphorescent OLEDs (PHOLEDs). ${ }^{1,2,10}$ The tendency of triplet excitons diffusing into the nonradiative sites of the neighboring hole transport layer (HTL) or electron transport layer (ETL) must be avoided to prevent the triplet energy loss. Lee et al. demonstrated that the efficiency of blue PHOLEDs based on iridium(III) bis[4,6-(difluorophenyl)-pyridinato- $\left.N, C^{2^{\prime}}\right]$ picolinate (FIrpic) is very sensitive to the triplet energy and carrier transport properties of the hole transporting materials. ${ }^{11}$ Goushi et al. reported that the triplet exciton confinement and unconfinement effects by the adjacent HTL have significant influence on the electrophosphorescent efficiency. ${ }^{12}$ Hung et al. revealed that carrierand exciton-confining structure not only enhanced blue PHOLED efficiency but also reduced efficiency roll-off. ${ }^{13}$ By confining charge carriers and triplet excitons in a narrow recombination zone, Su et al. demonstrated a WOLED with an external quantum efficiency (EQE) up to $25 \%$ at a luminance of $1000 \mathrm{~cd} / \mathrm{m}^{2}$, without any outcoupling techniques. ${ }^{14}$

\footnotetext{
${ }^{a)}$ Present address: Organic Semiconductor Centre, SUPA, School of Physics and Astronomy, University of St Andrews, KY16 9SS, United Kingdom.

${ }^{b)}$ Author to whom correspondence should be addressed. Electronic mail: xueqin19851202@163.com
}

In this paper, we introduced high triplet level $\operatorname{Ir}(\mathrm{ppz})_{3}$ as an electron/exciton blocking layer (EBL) between HTL and FIrpic-doped $N, N^{\prime}$-dicarbazolyl-3,5-benzene (mCP). To sense the dynamic of charge carriers and triplet excitons under operation, an ultrathin (nominal $0.1 \mathrm{~nm}$ ) layer deep-red emitter of $\operatorname{Ir}(\mathrm{piq})_{3}$ was inserted within EBL at a distance of $d \mathrm{~nm}$ away from the adjacent blue emissive layer (B-EML) which comprised FIrpic doped $\mathrm{mCP}$. To refrain the triplet exciton accumulation at both B-EML interfaces which consequently complicates the interplay between charge carriers and exciton within the narrow recombination zone $(5 \mathrm{~nm})$, we constructed a barrier-free orange emissive layer (O-EML) to efficiently quench the accumulated excitons. With such a structure, we are able to detect the leakage of electrons and diffusion of excitons from the B-EML to the ultrathin sensing layer, without significantly influencing the total amount of charge carriers injected from cathode and anode.

\section{EXPERIMENTAL DETAILS}

The molecular structure of the organic materials used in this work and the structure of the devices are depicted in Figure 1. We used 4,4', $4^{\prime \prime}$-tris(3-methylphenylphenylamino)triphenylamine ( $m$-MTDATA) as an efficient HTL. $\mathrm{MoO}_{\mathrm{x}}-$ based buffer layer and p-doped HTL are introduced to reduce the ohmic loss. $\operatorname{Ir}(\mathrm{ppz})_{3}$ which has extremely high triplet level was used as EBL. FIrpic doped $\mathrm{mCP}$ served as a blue phosphorescent emissive unit, and bis(2-(2-fluorphenyl)-1, 3-benzothiozolato-N, $\mathrm{C}^{2^{\prime}}$ )iridium(acetylacetonate) $\quad(\mathrm{F}-\mathrm{BT})_{2}$ (acac) doped $\mathrm{mCP}$ as an orange phosphorescent emissive unit. 4,7-diphenyl-1,10-phenanthroline (BPhen) acted as hole-blocking layer (HBL) and ETL. Bi-layer LiF/Al was chosen as the composite cathode. To sense the dynamic of charge carriers and excitons under bias, we inserted an 

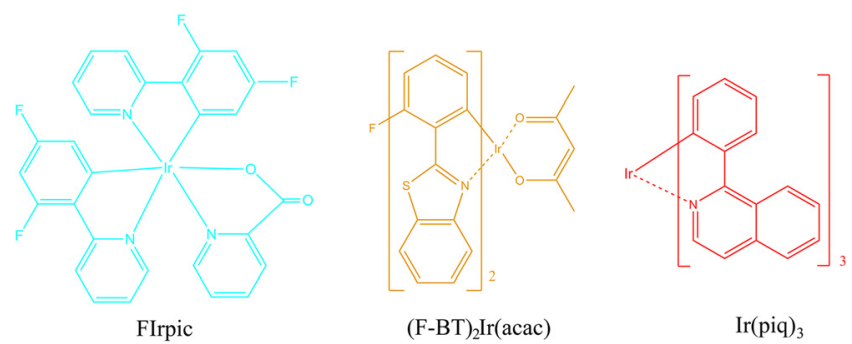

$(\mathrm{F}-\mathrm{BT})_{2} \operatorname{Ir}(\mathrm{acac})$

$\operatorname{Ir}(\text { piq })_{3}$

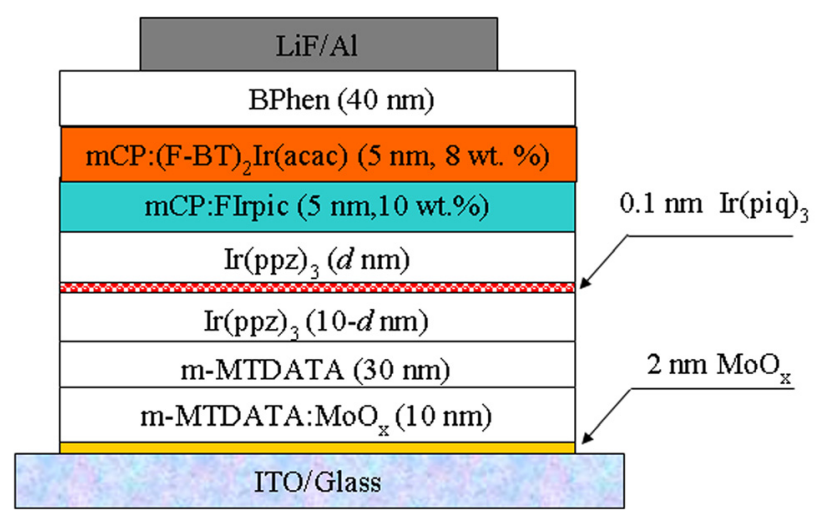

FIG. 1. The chemical structure of the phosphorescent dopants and the device architecture.

ultrathin $\operatorname{Ir}(\text { piq })_{3}$ layer into the $\operatorname{Ir}(\mathrm{ppz})_{3}$ layer at a distance of $d$ $\mathrm{nm}$ away from the $\operatorname{Ir}(\mathrm{ppz})_{3} / \mathrm{mCP}$ :Firpic interface. We fabricated devices $\mathrm{A}, \mathrm{B}, \mathrm{C}$, and $\mathrm{D}$ with $d=0,3,7$, and 10 , respectively. The devices were prepared by vacuum deposition onto indium tin oxide (ITO) coated glass substrates. Prior to the deposition of the organic layers, ITO-coated glass was cleaned by scrubbing and sonication. The organic layers were deposited by high-vacuum $\left(\sim 10^{-4} \mathrm{~Pa}\right)$ thermal evaporation with a rate of $0.1-0.2 \mathrm{~nm} / \mathrm{s}$. The layer thicknesses and the deposition rates of the organic and inorganic materials were monitored in situ by a quartz-crystal oscillator. Electroluminescent (EL) spectra, luminance, and Commission International de L'Eclairage (CIE) coordinates of the devices were measured by a PR650 spectra scan spectrometer, and the current-voltage characteristics were recorded simultaneously with a programmable Keithley 2400 source-meter unit. All measurements were carried out at room temperature under ambient conditions. EQE is determined by assuming a Lambertian distribution of the emission. ${ }^{15}$

\section{RESULTS AND DISCUSSION}

The normalized EL spectra of devices are shown in Figure 2. We can clearly observe the unambiguous emission from $\operatorname{Ir}(\mathrm{piq})_{3}$ in devices $\mathrm{A}$ and $\mathrm{B}$, which disappeared in devices $\mathrm{C}$ and D. Figure 3 compares the luminance-voltage (L-V) characteristics of the four devices, and the inset shows the current density-voltage $(\mathrm{J}-\mathrm{V})$ characteristics. It is noteworthy that the current density of the four devices are almost identical as the total thickness of the devices are the same and the ultrathin $\operatorname{Ir}(\text { piq })_{3}$ has little influence on the total amount of charge carriers injected from both anode and cathode no matter where such an ultrathin layer is. However,

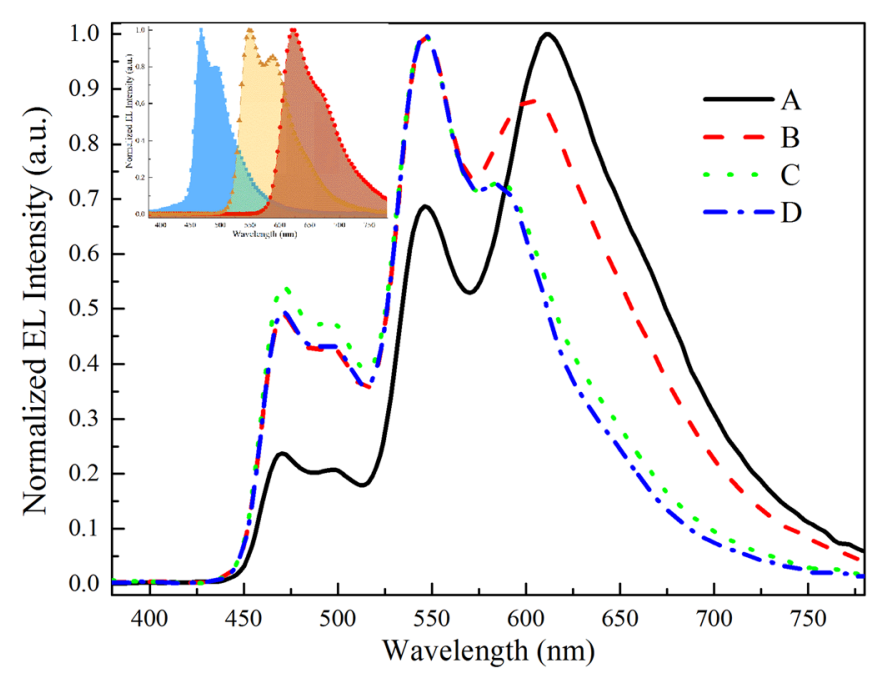

FIG. 2. Normalized EL spectra of the devices at $100 \mathrm{~mA} / \mathrm{cm}^{2}$. Inset: normalized EL spectra of the devices with only one emissive dopant, i.e., blue, orange, and red, respectively.

under the same bias, the luminance slightly increases as the sensing layer shifted towards the anode side.

The current and power efficiency vs. luminance curves are displayed in Figures 4(a) and 4(b), respectively. The current efficiency of device $\mathrm{A}$ is the lowest as the deep-red emission is dominant. Devices C and D exhibited quite similar current and power efficiencies. They achieved a similar current efficiency of $25.0 \mathrm{~cd} / \mathrm{A}$ at a luminance of $100 \mathrm{~cd} / \mathrm{m}^{2}$. For device B, only $16.7 \mathrm{~cd} / \mathrm{A}$ at $100 \mathrm{~cd} / \mathrm{m}^{2}$ was achieved. The maximum power efficiencies of devices $\mathrm{A}, \mathrm{B}, \mathrm{C}$, and D are $10.1,23.4,24.0$, and $15.2 \mathrm{~lm} / \mathrm{W}$, respectively.

To fully understand the mechanism behind the abovementioned phenomena, we schematically plotted the energy diagram of the devices in Figure 5. The highest occupied molecular orbital (HOMO) and the lowest unoccupied molecular orbital (LUMO) of $\operatorname{Ir}(\mathrm{piq})_{3}$ are 5.0 and $3.1 \mathrm{eV}$, respectively. The triplet energy of $\operatorname{Ir}(\text { piq })_{3}$ is much lower than that of FIrpic (shown in Figure 5(a)). Since the overlap of the wavefunctions is sufficient, there will be efficient Dexter energy transfer from triplet state of FIrpic to that of

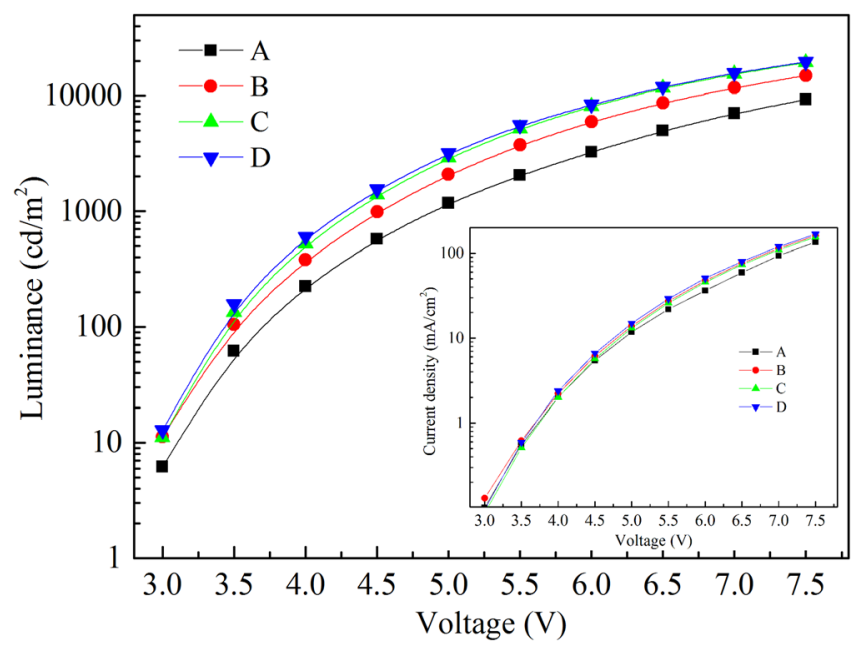

FIG. 3. Luminance-voltage characteristics of the devices. Inset: current density-voltage characteristics of the devices. 

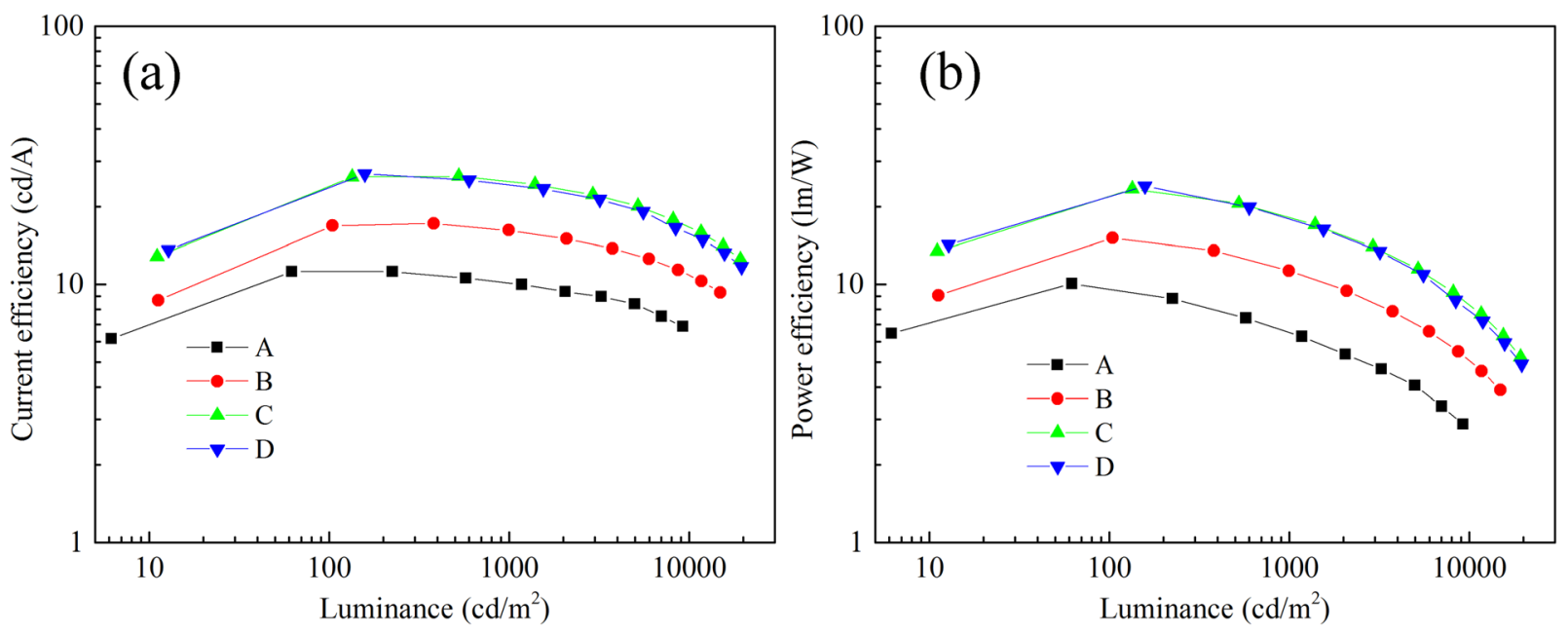

FIG. 4. Current efficiency (a) and power efficiency (b) vs. luminance characteristics of the devices.

$\operatorname{Ir}(\text { piq })_{3}$ in device $\mathrm{A}$ as $\operatorname{Ir}(\mathrm{ppz})_{3}$ is absent from B-EML interface. Meanwhile, direct carrier trapping in the $\operatorname{Ir}(\text { piq })_{3}$ layer sandwiched in device A would be apparent due to the low LUMO position and high HOMO position of $\operatorname{Ir}\left(\right.$ piq) ${ }_{3}$ (see Figure 5(b)). It is reasonable that the deep-red emission from $\operatorname{Ir}(\text { piq })_{3}$ dominates the EL spectrum of device A, which leads to typical warm white emission close to standard illuminant A. For device $\mathrm{B}(d=3 \mathrm{~nm}), \operatorname{Ir}(\text { piq })_{3}$ is separated from mCP:FIrpic by $3 \mathrm{~nm}$ thick pristine $\operatorname{Ir}(\mathrm{ppz})_{3}$ while the total thickness of the device keeps constant. However, $3 \mathrm{~nm}$ thick $\operatorname{Ir}(\mathrm{ppz})_{3}$ which has a very high triplet level of $3.1 \mathrm{eV}$ is not potentially enough to completely block all the electrons from penetrating through the $\operatorname{Ir}(\mathrm{ppz})_{3} / \mathrm{B}-\mathrm{EML}$ interface. Meanwhile, the triplet excitons can diffuse into the ultrathin red emissive sites due to the concentration gradient at the interface. Consequently, some amount of the electrons will tunnel through this thin $\operatorname{Ir}(\mathrm{ppz})_{3}$ layer and be trapped by $\operatorname{Ir}(\text { piq })_{3}$. As the thickness of $\operatorname{Ir}(\mathrm{ppz})_{3}$ was increased to $7 \mathrm{~nm}$, we found that the emission from $\operatorname{Ir}(\text { piq })_{3}$ disappeared. This

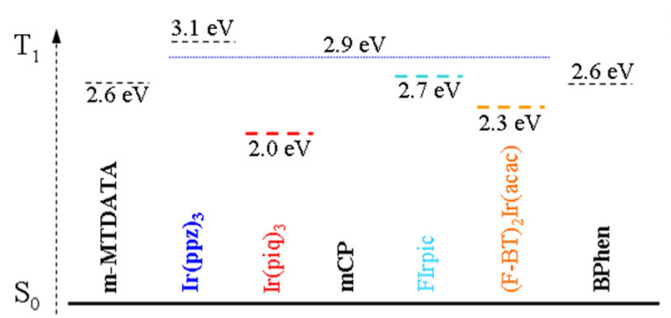

(a)

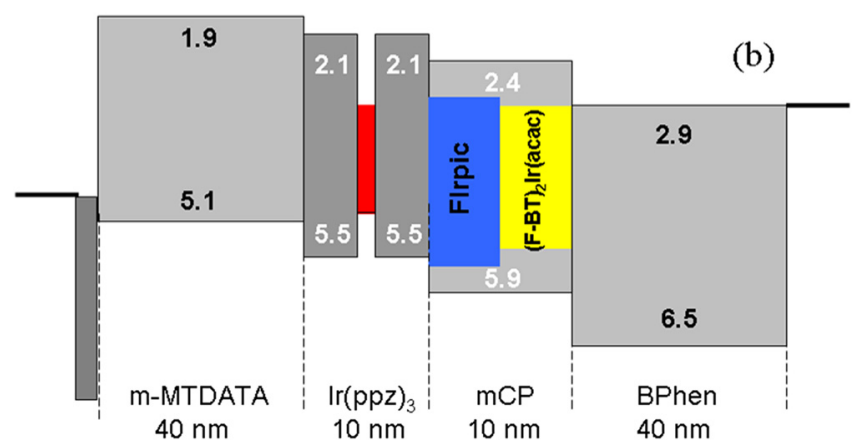

FIG. 5. (a) Comparison of the triplet energy level of the organic materials and (b) schematic energy level diagram of the devices. provides strong evidence that $7 \mathrm{~nm} \operatorname{Ir}(\mathrm{ppz})_{3}$ is sufficient to prevent the leakage of electrons and diffusion of excitons towards the anode side from the B-EML. In Figure 2, it is evident that blue emission from device $\mathrm{D}$ decreased relatively to orange emission from (F-BT) ${ }_{2} \operatorname{Ir}(\mathrm{acac})$ compared with that of device $\mathrm{C}$. The ultrathin $\operatorname{Ir}(\mathrm{piq})_{3}$ layer lies exactly at m-MTDATA/Ir(ppz $)_{3}$ interface in device D, which makes the hole trapping effect of $\operatorname{Ir}(\text { piq })_{3}$ very efficient. It might result in less holes reach the B-EML and more electrons accumulated at the thicker $\operatorname{Ir}(\mathrm{ppz})_{3}(10 \mathrm{~nm}) / \mathrm{B}-\mathrm{EML}$ interfaces due to local electrostatic force. As a result, the imbalance of holes and electrons in the main recombination zone, i.e., B-EML and O-EML, accounts for the inferior luminous efficiency of device $\mathrm{D}$.

To further understand the dynamic of charge carriers and excitons under operation, we compared the normalized EL spectra of the devices under different driving voltages, shown in Figures 6(a)-6(d). As we can see, all the spectra are normalized to the peak intensity of $(\mathrm{F}-\mathrm{BT})_{2} \operatorname{Ir}(\mathrm{acac})$. Obviously, the emission of $\operatorname{Ir}(\text { piq })_{3}$ decreased with increasing voltages in both devices $\mathrm{A}$ and $\mathrm{B}$, while the emission of FIrpic kept relatively constant in device A and slightly increased in device B. As $\operatorname{Ir}(\mathrm{piq})_{3}$ acted as efficient hole and electron trapping sites in our structure, with increasing driving voltage most of the trapping sites are filled and therefore more holes could reach the B-EML and O-EML, which contributes to the relatively increased blue and orange emission, i.e., reduced red emission. For device A, we supposed that charge carriers and excitons are evenly distributed in B-EML and O-EML. At the same time, the triplet energy exchange between B-EML and O-EML is almost under equilibrium. Once the voltage is increased, the excessive electrons reach the B-EML/Ir(piq) $)_{3}$ interface. Consequently, they will be trapped by $\operatorname{Ir}(\text { piq })_{3}$ directly until all the trapping sites are filled. The excessive excitons close to this interface will be quenched by $\operatorname{Ir}(\text { piq })_{3}$ as well. That is why the ratio of blue and orange emission from device $\mathrm{A}$ is nearly independent on the biases. To design a device with high color stability and high color-rendering index, we should prevent this charge carrier trapping process in $\operatorname{Ir}($ piq) 3 but remain the Dexter energy transfer path. Based on this concept, a 

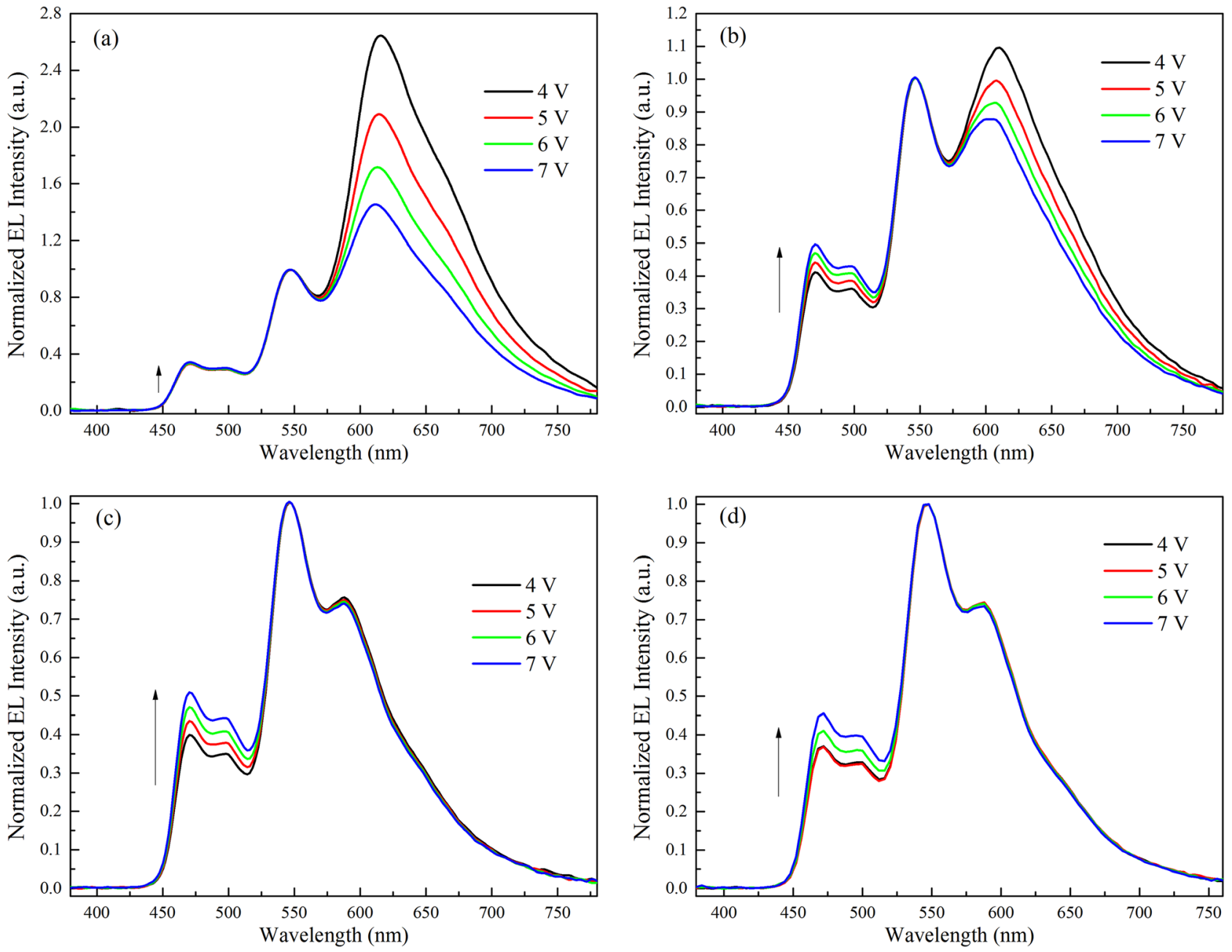

FIG. 6. (a)-(d) Normalized EL spectra of devices A, B, C, and D, respectively, under different biases.

phosphorescent emitter with lower triplet level than FIrpic but slightly higher LUMO position than FIrpic would contribute to extremely color-stable white emission by replacing $\operatorname{Ir}(\text { piq })_{3}$ in our structure. To our delight, Zhang et al. demonstrated color-stable phosphorescent WOLEDs with yellow/ blue/yellow architecture in which FIrpic based EML is sandwiched between two bis(2-phenylbenzothiazolato) (acetylacetonate)iridium(III) $\left(\mathrm{Ir}(\mathrm{bt})_{2}(\mathrm{acac})\right)$ based EMLs. ${ }^{16}$ This is consistent with the above-mentioned conclusion.

At the presence of $\operatorname{Ir}(\mathrm{ppz})_{3}$ between the ultrathin $\operatorname{Ir}(\mathrm{piq})_{3}$ and B-EML, the electrons are not trapped directly but partially blocked by the interface. Interestingly, we observed
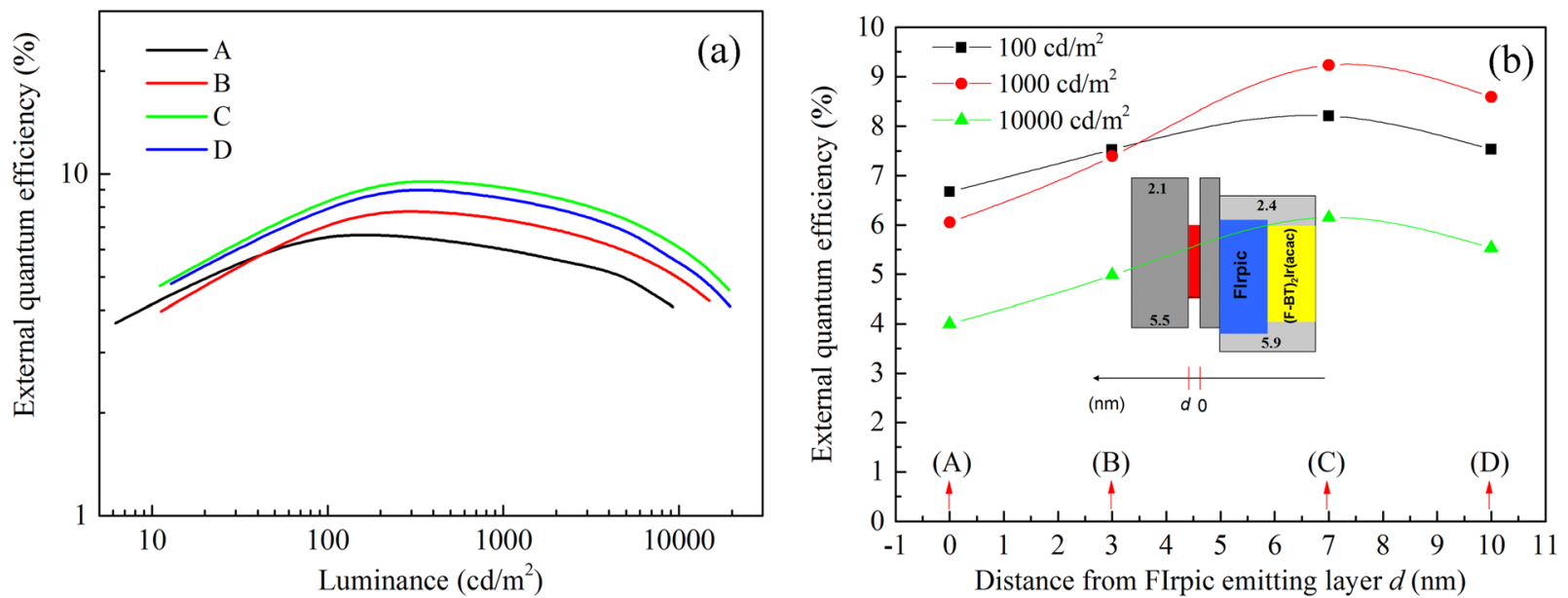

FIG. 7. (a) The external quantum efficiency of the four devices. (b) The dependence of external quantum efficiency on luminance and Ir(piq) 3 position. The inset indicates the position of $0.1 \mathrm{~nm}$ thick $\operatorname{Ir}(\text { piq) })_{3}$. 
that the blue emission from FIrpic gradually increased as the driving voltage increased. Now it is clear that more electron accumulated at the $\operatorname{Ir}(\mathrm{ppz})_{3} / \mathrm{B}-\mathrm{EML}$ interface in devices $\mathrm{B}$, $\mathrm{C}$, and D as the bias increased (see Figures 6(a)-6(d)). We compared the luminance and $\operatorname{Ir}(\text { piq })_{3}$ position dependent EQE characteristics in Figures 7(a) and 7(b). The EQE tends to increase as $\operatorname{Ir}(\text { piq })_{3}$ is moving away from FIrpic based B-EML at all different luminance levels. Now we confirm that, at both interfaces of B-EML, Dexter energy transfer dominates the triplet energy exchange/conversion between the two adjacent phosphorescent emitters. With an efficient $\mathrm{EBL}$, it is more likely to observe strong blue emission from a structure of anode/.../blue/yellow/.../cathode. In contrast, the blue phosphorescent emission from FIrpic is significantly reduced once no EBL is used, i.e., the triplet loss to non-radiative sites of the adjacent HTL. Interestingly, due to the superior electron transport ability of FIrpic and strong charge carrier trapping effect in lower band-gap yellow EML, ${ }^{17}$ it is quite common that only feeble blue emission from a structure of anode/.../yellow/blue/.../cathode, simply swapping the blue and yellow EMLs. ${ }^{18-20}$ This phenomenon can be compensated by reducing the doping concentration of yellow emitter to very low level or introducing an interlayer between the blue and yellow EMLs, for the sake of designing a balanced white emission. This might make a white device even more complicated.

For an illustrative purpose, we schematically plotted the dynamic of charge carriers and exciton in Figures 8(a)-8(d) for the respective four devices. In Figure 8(a), we can conclude that the triplet energy transfer is predominant in the red emission which contributes to the candle-like spectra of device A with a correlated color temperature (CCT) of $2561 \mathrm{~K}$. However, due to the large triplet energy gap $(\sim 0.7 \mathrm{eV})$ between FIrpic and $\operatorname{Ir}(\mathrm{piq})_{3}$, this process is not efficient enough. Therefore, a loss of the triplet energy is predictable by comparing the EQE in Figures 7(a) and 7(b). As the red emitter moving away from the B-EML, both of the efficiency and CCT increase. In device B, both trap-assisted recombination and triplet exciton diffusion/energy transfer contribute to the residual $\operatorname{Ir}(\mathrm{piq})_{3}$ emission. If only trap-assisted recombination exists in device $\mathrm{B}$, it is not likely to observe an increase of EQE in device $\mathrm{C}$ (see Figures 7(a) and 7(b)). In contrast, we would not be able to see an increase of the blue emission in device B (compared to device A) if only triplet exciton diffusion/energy transfer plays a role in the red emission in device B (see Figure 2). The small increase of the blue emission in device $\mathrm{C}$ indicates that it is nearly impossible for the triplet excitons from B-EML diffusing into the ultrathin $\operatorname{Ir}(\mathrm{piq})_{3}$ layer. Meanwhile, the EQE of device $C$ reaches the peak value of all the four devices as the triplet excitons are well confined in B-EML with an internal quantum efficiency up to unity. Otherwise, the electrons tend to be completely blocked by $10 \mathrm{~nm} \operatorname{Ir}(\mathrm{ppz})_{3}$, which results in more electrons accumulated at $\operatorname{Ir}(\mathrm{ppz})_{3} / \mathrm{B}-\mathrm{EML}$ interface and consequently the energy loss in the forms of triplet-triplet annihilation and triplet-polaron quenching. Thus the drop of the EQE of device $\mathrm{D}$ is reasonable (see Figure 7(b)).

Figure 9 shows that the variation of CIE coordinates is somewhat dependent on the position of the ultrathin $\operatorname{Ir}(\text { piq })_{3}$ sensing layer. When the sensing layer is close to B-EML, the obvious color shift is detectable. Once the sensing layer
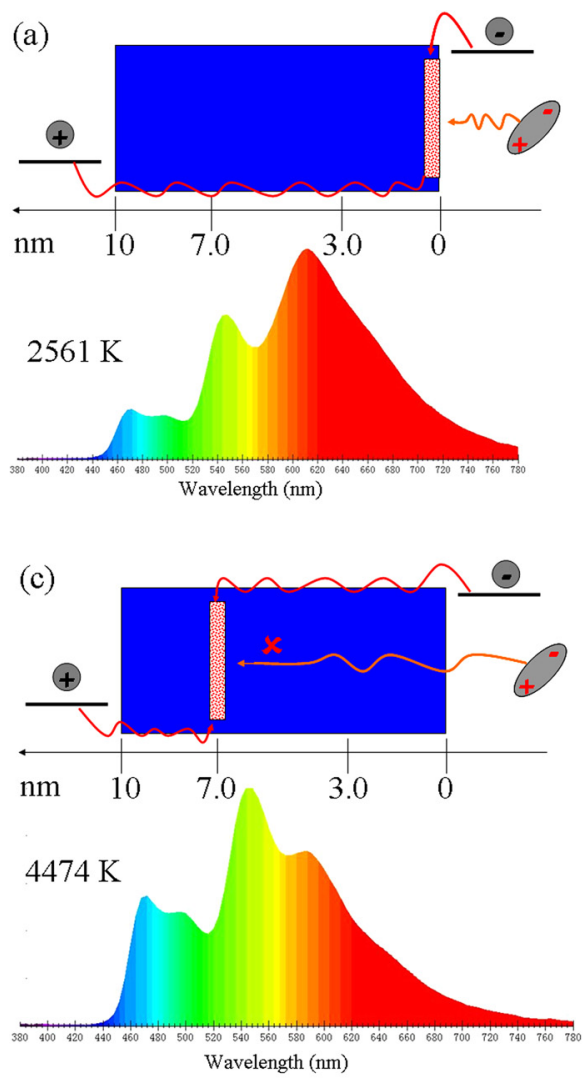
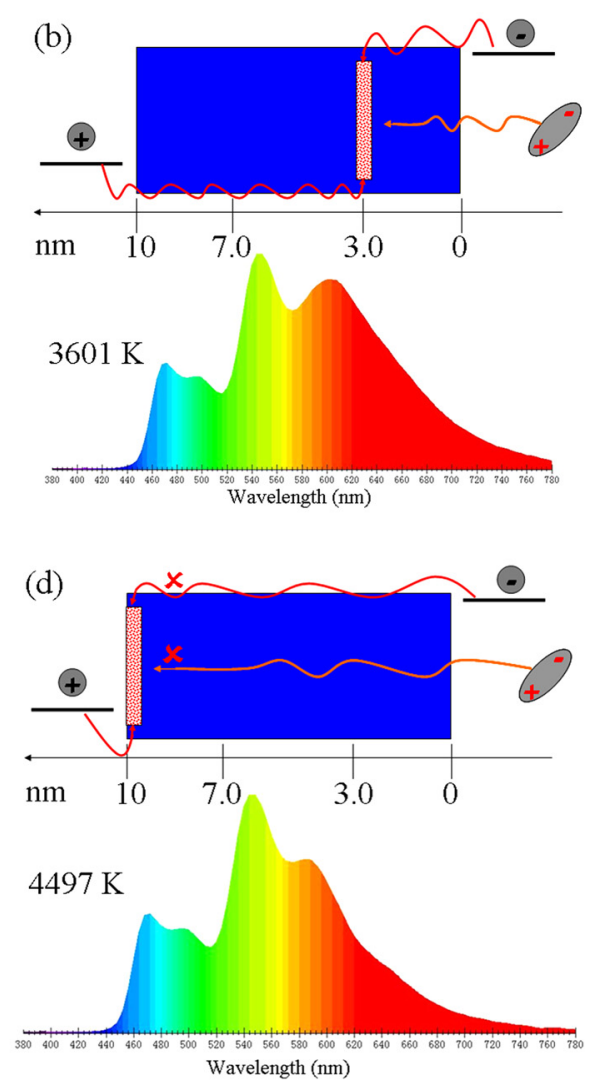

FIG. 8. (a)-(d) Schematic diagram of dynamic of charge carriers and excitons and the corresponding EL spectra at $100 \mathrm{~mA} / \mathrm{cm}^{2}$ of the device $\mathrm{A}, \mathrm{B}, \mathrm{C}$, and $\mathrm{D}$. The indicated CCT is a function of the position of the ultrathin $\operatorname{Ir}(\mathrm{ppz})_{3}$ layer. 


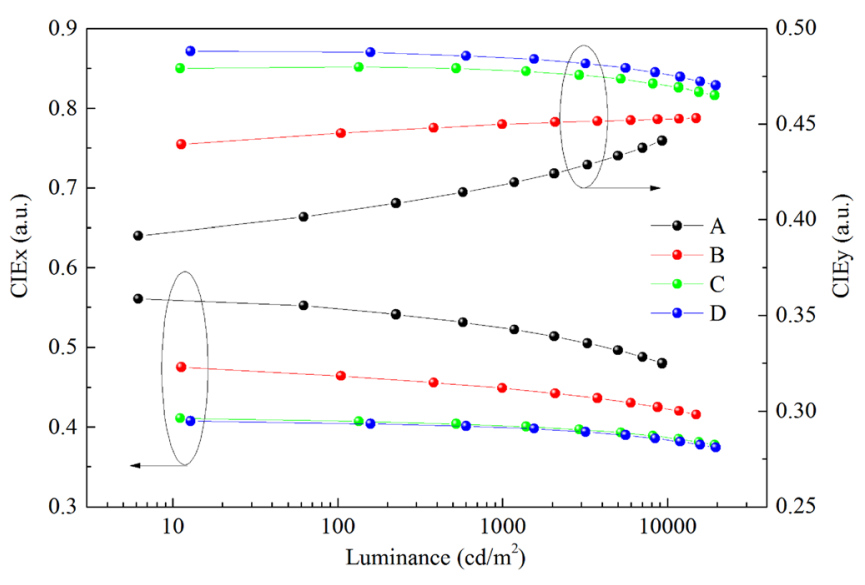

FIG. 9. The CIE coordinates vs. luminance characteristics of the devices.

deviated from the main recombination zone, the emission color turns to be unchanged. This provides us a very simple and reproducible way to control the emission color of WOLED by shifting of the $\operatorname{Ir}(\text { piq })_{3}$ sensing layer position and monitor the charge carrier and exciton dynamic. Overall, the devices with the ultrathin red emitter provide much lower color shift than the all-phosphorescent devices with broad triple emissive zones which leads to the fluctuation of charge carriers and triplet excitons at the interfaces due to the change of the potential.

\section{CONCLUSIONS}

In conclusion, we qualitatively investigated the evolution of EL performance of all-phosphorescent OLEDs combining an ultrathin $(0.1 \mathrm{~nm})$ and two adjacent $(5 \mathrm{~nm})$ emissive zones. An ultrathin $\operatorname{Ir}(\text { piq })_{3}$ at different position of the EBL significantly influences luminance and efficiencies. By simply inserting $0.1 \mathrm{~nm} \operatorname{Ir}(\mathrm{piq})_{3}$ at EBL/B-EML interface, very broad-band emission ranging from 450 to $780 \mathrm{~nm}$ is achievable. Once this sensing layer shifts away from this interface, the deep-red emission is fading. At the presence of this sensing layer at the interface, $\operatorname{Ir}(\text { piq })_{3}$ directly harvests the triplet energy from FIrpic. At $7 \mathrm{~nm}$ away from this interface, no more deep-red emission can be detected. No more triplet exciton can diffuse into/beyond this position and the electrons are completely blocked as well. We experimentally distinguished that the diffusion length of the triplet exciton in a $5 \mathrm{~nm}$ thick FIrpic-based emission zone is within the range of 3-7 nm. However, the penetration depth of the electrons into $\operatorname{Ir}(\mathrm{ppz})_{3}$ is within the range of $7-10 \mathrm{~nm}$. As the sensing layer moves away, more holes are trapped by the $\operatorname{Ir}(\mathrm{piq})_{3}$ sites at low bias and more electrons accumulated at EBL/B-EML interface due to local electrostatic force. As expected, tuning of color rendering index, correlated color temperature, luminance, and efficiencies can be simply controlled by such a sensing layer.

\section{ACKNOWLEDGMENTS}

We acknowledge fund from the National Key Basic Research and Development Program of China under Grant No. 2010CB327701. Q. Xue acknowledges support from Fundamental Research Funds for the Central Universities and China Scholarship Council.

${ }^{1}$ Y. Sun and S. R. Forrest, Org. Electron. 9, 994-1001 (2008).

${ }^{2}$ Y. Sun, N. C. Giebink, H. Kanno, B. Ma, M. E. Thompson, and S. R. Forrest, Nature 440, 908-912 (2006).

${ }^{3}$ G. Schwartz, M. Pfeiffer, S. Reineke, K. Walzer, and K. Leo, Adv. Mater. 19, 3672-3676 (2007)

${ }^{4}$ K. T. Kamtekar, A. P. Monkman, and M. R. Bryce, Adv. Mater. 22, 572-582 (2010).

${ }^{5}$ B. W. D'Andrade and S. R. Forrest, Adv. Mater. 16, 1585-1595 (2004).

${ }^{6}$ S. K. Jones and W. E. Howard, Laser Focus World 37, 55 (2001).

${ }^{7}$ Y. Sun and S. R. Forrest, Appl. Phys. Lett. 91, 263503 (2007).

${ }^{8}$ S. Tokito, T. Iijima, T. Tsuzuki, and F. Sato, Appl. Phys. Lett. 83, 2459-2461 (2003).

${ }^{9}$ S. H. Kim, J. Jang, and J. Y. Lee, Appl. Phys. Lett. 91, 123509 (2007).

${ }^{10}$ S. Reineke, F. Lindner, G. Schwartz, N. Seidler, K. Walzer, B. Lussem, and K. Leo, Nature 459, 234-238 (2009).

${ }^{11}$ J. Lee, N. Chopra, S.-H. Eom, Y. Zheng, J. Xue, F. So, and J. Shi, Appl. Phys. Lett. 93, 123306 (2008).

${ }^{12}$ K. Goushi, R. Kwong, J. J. Brown, H. Sasabe, and C. Adachi, J. Appl. Phys. 95, 7798-7802 (2004).

${ }^{13}$ W.-Y. Hung, Z.-W. Chen, H.-W. You, F.-C. Fan, H.-F. Chen, and K.-T. Wong, Org. Electron. 12, 575-581 (2011).

${ }^{14}$ S.-J. Su, E. Gonmori, H. Sasabe, and J. Kido, Adv. Mater. 20, 4189-4194 (2008).

${ }^{15}$ Q. Huang, S. Reineke, K. Walzer, M. Pfeiffer, and K. Leo, Appl. Phys. Lett. 89, 263512 (2006).

${ }^{16}$ Z. Zhang, G. Xie, S. Yue, Q. Wu, Y. Chen, S. Zhang, L. Zhao, Y. Luo, Y. Zhao, and S. Liu, Org. Electron. 13, 2296-2300 (2012).

${ }^{17}$ J. Lee, J.-I. Lee, J. Y. Lee, and H. Y. Chu, Appl. Phys. Lett. 94, 193305 (2009).

${ }^{18}$ Y.-S. Seo and D.-G. Moon, J. Soc. Inf. Disp. 18, 1010-1014 (2010).

${ }^{19}$ S.-L. Lai, S.-L. Tao, M.-Y. Chan, M.-F. Lo, T.-W. Ng, S.-T. Lee, W.-M. Zhao, and C.-S. Lee, J. Mater. Chem. 21, 4983-4988 (2011).

${ }^{20}$ S.-L. Lai, W.-Y. Tong, S. C. F. Kui, M.-Y. Chan, C.-C. Kwok, and C.-M. Che, Adv. Funct. Mater. 23, 5168-5176 (2013). 